\title{
A Comparative Study of Anxiety in Indonesia and Nepal During COVID-19 Pandemic
}

\section{Yeseul Jung}

Yonsei University

\section{Sukri Palutturii}

Hasanuddin University: Universitas Hasanuddin

\section{Dong Eun Shin}

Yonsei University

Eun Woo Nam ( $\square$ ewnam@yonsei.ac.kr)

Yonsei University

\section{Research article}

Keywords: COVID-19, Indonesia, Nepal, Anxiety

Posted Date: December 14th, 2020

DOl: https://doi.org/10.21203/rs.3.rs-125363/v1

License: (9) This work is licensed under a Creative Commons Attribution 4.0 International License. Read Full License 


\section{A Comparative Study of Anxiety in Indonesia and Nepal During COVID-19}

\section{Pandemic}

Yeseul Jung ${ }^{1}$, Sukri Palutturii ${ }^{4}$, Dong Eun $\mathrm{Shin}^{2}$, Eun Woo Nam ${ }^{3} \dagger$

${ }^{1}$ Ph.D. course, Department of Health Administration, Graduate School, Yonsei University, Republic of Korea

${ }^{2}$ Post-doctoral, Department of Health Administration, Graduate School, Yonsei University, Republic of Korea

${ }^{3}$ Professor, Department of Health Administration, Yonsei University, Republic of Korea

${ }^{4}$ Professor, Hasanuddin University, Indonesia

$\dagger$ Corresponding: Eun Woo Nam

Unit 415, Changjo-kwan, Yonsei University, Yonseidaegil1, Heungeop-myeon, Wonju-si, Gangwon-do, Republic of Korea, 26493

Tel: +82-33-762-2413, Fax: +82-33-762-9562, E-mail: ewnam@yonsei.ac.kr 


\begin{abstract}
Indonesia and Nepal, which are in the World Health Organization South-East Asia Region, are the countries with the highest numbers of confirmed cases and deaths since the start of the COVID-19 pandemic outside of the Region of the Americas and the European Region. Since its first confirmed case on March $2^{\text {nd }}$, Indonesia has reported 100,303 cases and 4,838 deaths as of July 28, which is the highest number of cases in Southeast Asia. As restrictions in response to the pandemic continue, the public's psychological anxiety is gradually increasing. There were 889 participants (university students and graduate students) living in Indonesia or Nepal (Indonesia: 551 persons; Nepal: 338 persons). An English questionnaire was administered to participants through an online survey using Google. Regarding the factors affecting anxiety, they were "trust in hospitals for COVID-19 diagnosis," "risk of getting infected by COVID-19," "risk of family getting infected by COVID-19," "national discrimination due to COVID-19," "chronic disease status," "experience of purchasing masks," and "health behaviors" in Indonesia, and "trust in hospitals for COVID-19 diagnosis," "risk of family getting infected by COVID-19," and "depression score" in Nepal. In both countries, significant effects of "trust in hospitals for COVID-19 diagnosis" and "risk of family getting infected by COVID-19" were observed. Therefore, Indonesia and Nepal should implement policies and guidelines to prevent psychological and psychiatric issues in the population due to the COVID-19 pandemic. Such measures will help to prevent and control the secondary damage caused by the disease.
\end{abstract}

\title{
Key Words
}

COVID-19, Indonesia, Nepal, Anxiety 


\section{Introduction}

Since first emerging in China in December 2019, Coronavirus disease (COVID-19) has spread rapidly on a global scale, resulting in massive numbers of infected patients and deaths. Due to the high rate of transmission, countries worldwide have been making efforts to prevent further spread, such as restricting movement, locking down international borders, as well as other country-specific regulations. Indonesia and Nepal, which are countries in the World Health Organization (WHO) South-East Asia Region, have both experienced the highest numbers of confirmed cases and deaths since the start of the COVID-19 pandemic outside of the Region of the Americas and the European Region. Since its first confirmed COVID-19 patient on March $2^{\text {nd }}$, Indonesia has recorded 100,303 confirmed cases and 4,838 deaths as of July $28^{\text {th }}$, which was the highest number of confirmed cases in Southeast Asia [1].

The Indonesian government implemented large-scale social restrictions (Pembatasan Sosial Berskala Besar, PSBB), affecting the use of educational institutions, workplaces, religious facilities, public facilities, cultural activities, and transport, and temporarily closed locations and facilities with dense crowds. Travel between regions has been forbidden, and the international airports have also ceased operations. Following the announcement of the PSBB, the "new normal" period was promulgated, and conditions for movement domestically and overseas were strictly enforced, such as submission of polymerase chain reaction test (COVID-19 test) results. However, due to the weather in Indonesia, the number of cases has continued to increase, leading the Indonesian government to announce an extension of the PSBB to July $30^{\text {th }}[2]$.

In Nepal, the first case of COVID-19 was a Nepalese national who re-entered the country from China on January $23^{\text {rd }}$. Since then, there have been 18,752 confirmed cases and 48 deaths reported as of July $28^{\text {th }}$, and these numbers continue to grow. On March 22nd, the Nepalese government implemented entry restrictions for international flights and tourists to prevent the entry of COVID-19 from overseas and implemented nationwide lockdown on March $24^{\text {th }}$. The lockdown measures successfully reduced the spike in cases and deaths, and the national lockdown was ended on July $21^{\text {st }}[3]$.

As these restrictions continue, the psychological anxiety of the public is gradually increasing. Anxiety refers to feelings of tension, worrisome thoughts, and emotions affecting the body, which presents with unwanted thoughts and worries and can also develop when an individual try to avoid their worries [4]. Anxiety and depression can increase when trauma-induced thoughts or moods are recalled as well as in survivors of certain incidents. Such 
incidents make people feel different emotions from normal and can cause various symptoms, such as reduced concentration, loss of appetite, mood swings, and sleep disturbance [5]. In China, the first country to implement a lockdown, $21.3 \%$ of students at Changzhi Medical College experienced mild anxiety, $2.7 \%$ experienced moderate anxiety, and $0.9 \%$ experienced severe anxiety [6]. The main causes of anxiety were found to be the economic effects of COVID-19, effects on daily living, and delay of academic activities. In a study by Li et al., the prevalence of depression or anxiety among Chinese people was $20.4 \%$, and the onset of depression or anxiety was significantly related to the time of encountering news related to COVID-19. Other factors affecting anxiety included concerns about loved ones getting infected, concerns about income, employment, academic pursuits, or ability to repay loans, and discomfort in daily living due to isolation [7]. Wang et al. conducted a study of residents in 194 cities in China and found that $28.8 \%$ of respondents displayed moderate or severe anxiety symptoms. Moreover, the respondents were worried about the concerns about other family members getting COVID-19. Psychological effects, stress, anxiety, and depression were found to be higher among individuals who were female, students, those who had physical symptoms, or had low self-rated health [8]. The WHO has highlighted that, as the COVID-19 pandemic continues long-term, in addition to physical problems, psychiatric problems are becoming more prevalent worldwide, and many people are showing anxiety about the possibility of infection, death, or bereavement due to COVID-19 [9]. Hence, in this study, we aimed to compare anxiety between residents of Nepal and Indonesia, where long-term lockdown measures are continuing and the numbers of COVID-19 patients are growing, and to investigate the factors affecting anxiety. The specific objectives of this study were as follows:

1) To investigate general and healthcare-related characteristics in residents of Nepal and Indonesia

2) To investigate differences in healthcare-related characteristics and anxiety between residents of Nepal and Indonesia

3) To investigate factors affecting anxiety in the residents of Nepal and Indonesia

\section{Research Method}

\section{1) Research Design}

This study is a cross-sectional study and classified the factors affecting anxiety into general factors and health- 
related factors.

\section{2) Research tool and target}

The study participants were 889 individuals (university students and graduate students) from Indonesia ( $\mathrm{n}=551$ ) and Nepal (n=338). An English version of a questionnaire was conducted using Google online survey. The number of samples was calculated with an error limit of 5\% and a significance level of $95 \%$ using G Power 3.1.9.4. The minimum required number of samples was 76 , and sampling was conducted considering the dropout rate and insufficient questionnaire.

3) Method of data collection

Data was collected by online survey, a non-face-to-face survey method due to movement restrictions and quarantine by the Indonesian and Nepalese governments to prevent the spread of COVID-19 and using the snowball sampling method. The study was investigated for 24 days from April 7 to 30, $2020<$ Image1 $>$.

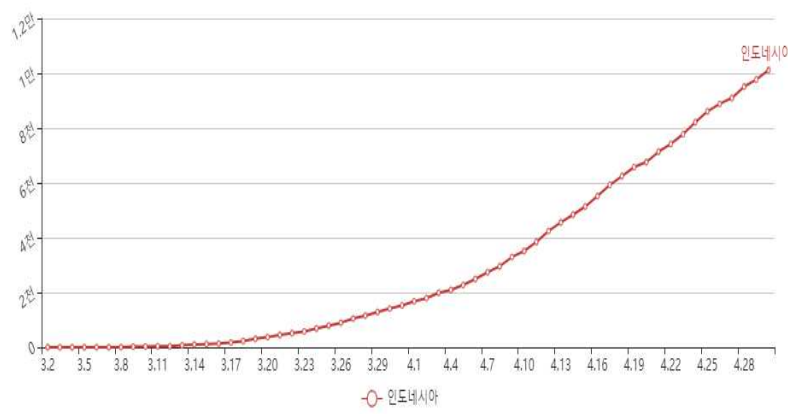

Confirmed cases in Indonesia: 10,118

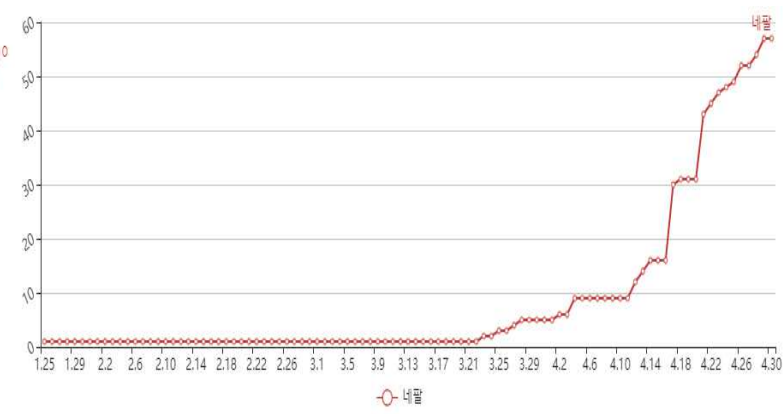

Confirmed cases in Nepal: 57

$<$ Image1 $>$ Confirmed case in Indonesia and Nepal (30. April. 2020)

\section{4) Research tool}

This study used the questionnaire developed by Y Global Health Center. The questionnaire included general characteristics questions: demographic characteristics and self-rated health, symptoms of discomfort, reliability of medical institutions, knowledge information about COVID-19 and health-related questions: possibility of COVID-19 infection and family infection, national discrimination due to COVID-19, purchase of mask, depression (PHQ-9, Patient Health Questionnaire-9). In case of PHQ-9, it was calculated by a total of 27 points 
by assigning 3 points to each question. In addition, the score was divided by 5, 10, 15 points as criteria to verify either has mild depression or not.

To measure "anxiety" caused by COVID-19, the question "Do you feel that too worry or anxiety has been made about COVID-19?" was applied. There were nine questions regarding health behaviors. The specific questions included over the last 14 days, covering your mouth when coughing and sneezing, using public transportation, washing hands with soap, washing hands after coughing and sneezing, wearing a mask regardless of symptoms, washing hands after touching contaminated objects, using an elevator, and sitting in a row, and whether or not to participate in meeting with 10 or more people. It was calculated by a total of 45 points by assigning 5 points to each question.

\section{Results}

1) General characteristics and healthcare-related characteristics

When the general and healthcare-related characteristics were compared between the residents of Indonesia and Nepal, among general characteristics, there were significant differences in sex $(\mathrm{p}<.001)$, age $(\mathrm{p}<.001)$, education level $(p<.001)$, marital status $(p<.001)$, employment status $(p<.001)$, presence or absence of children $(p<.001)$, and household size $(p<.001)$. There were no differences in whether or not the respondent had seen a doctor in the last 14 days $(\mathrm{t}=1.769, p=.184)$ or chronic disease status $(\mathrm{t}=.438, p=.508)<$ Table1 $>$.

The general characteristics of participants from Indonesia were as follows: $90.7 \%$ of respondents were female, and their mean age was $19.92 \pm 1.17$ years, with a range of 16-26 years. Most respondents were unmarried (99.6\%) and did not have children (96.0\%). The most commonly reported household size was 3-5 persons (55.5\%). In Nepal, $39.6 \%$ of respondents were male and $60.4 \%$ were female, and their mean age was $23.40 \pm 5.18$ years. Most respondents were unmarried (89.3\%), and 89.3\% were students. The most commonly reported household size was $3-5$ persons $(68.3 \%)$.

The healthcare-related characteristics for participants from Indonesia were as follows: $82.6 \%$ of respondents had experience of self-isolation, and subjective health status was reported as "good" by $58.4 \%$ of respondents and "very good" by $37.4 \%$. Trust in hospitals for COVID-19 diagnosis was rated as "somewhat confident" by $39.0 \%$ of respondents and "very confident" by $20.3 \%$. Regarding the contracting COVID-19 during the current outbreak, $39.2 \%$ of respondents rated the risk as "high" and $22.0 \%$ rated the risk as "very high." Regarding the risk of dying 
from COVID-19, 41.7\% of respondents rated the risk as "high" and 27.9\% rated the risk as "very high." Regarding the concerns about other family members getting COVID-19, 65\% of respondents stated that they were "very worried," and the percentage of respondents stating that there was national discrimination due to COVID-19 was $23.0 \%$. Further, $75.7 \%$ of respondents had purchased masks to prevent COVID-19 while $82.6 \%$ of respondents wanted additional information about COVID-19. The mean score for health behaviors was $34.1 \pm 7.73$ out of 45 points, and the mean anxiety score was $3.74 \pm 1.1$ points.

In Nepal, subjective health status was reported to be "good" by $58 \%$ of respondents and "very good" by $32.5 \%$, while trust in hospitals for COVID-19 diagnosis was rated as "low' by $47.6 \%$ of respondents and "medium" by 31.7\%. Regarding contracting COVID-19 during the current outbreak, $43.8 \%$ of respondents rated the risk as "high"; regarding the risk of dying from COVID-19, 53\% of respondents rated the risk as "high" and 34.3\% rated the risk as "very high." In total, $68 \%$ of respondents stated that there was no national discrimination due to COVID-19, 86.1\% stated that they had purchased masks to prevent COVID-19, and 86.1\% wanted additional information about COVID-19. The mean score for health behaviors was $15.33 \pm 5.26$ out of 45 points, and the mean anxiety score was $3.11 \pm 1.04$ points.

\section{2) Differences in anxiety depending on general and healthcare-related characteristics}

Among participants from Indonesia, trust in hospitals for COVID-19 diagnosis, contracting COVID-19 during the current outbreak, concerns about other family members getting COVID-19, national discrimination due to COVID-19, experience of purchasing masks, chronic disease status, desire for more information about COVID19, and health behaviors exhibited statistically significant relationships with anxiety. Participants with very high trust in hospitals for COVID-19 diagnosis exhibited the highest anxiety levels $(\mathrm{F}=2.797, p=.026)$, and participants who rated the contracting COVID-19 during the current outbreak as "very high" also exhibited high anxiety levels $(\mathrm{F}=4.515, p=.001)<$ Table2>. For concerns about other family members getting COVID-19, participants who responded "not applicable" exhibited the highest anxiety, followed by participants who stated that they were "very worried" ( $\mathrm{F}=13.4144, p<.001)$. Participants who stated that there was national discrimination due to COVID-19 exhibited higher anxiety $(\mathrm{F}=7.096, p=.001)$. Participants who had purchased masks exhibited higher anxiety $(\mathrm{t}=4.717, p<.001)$, and those with a chronic disease exhibited higher anxiety $(\mathrm{t}=-2.729, p=.007)$. Participants who 
wanted additional information about COVID-19 exhibited higher anxiety scores than those who did not want additional information $(\mathrm{t}=2.116, p=.035)$. There was a positive correlation between health behavior scores and anxiety scores $(\mathrm{r}=0.135, p=.003)$.

Among participants from Nepal, subjective health status, contracting COVID-19 during the current outbreak, national discrimination due to COVID-19, health behavior scores, concerns about other family members getting COVID-19, and depression scores exhibited statistically significant relationships with anxiety. Participants who reported "average" subjective health status exhibited higher anxiety $(\mathrm{F}=2.86, p=.018)$. Participants who rated contracting COVID-19 during the current outbreak as "very high" $(\mathrm{F}=2.519, p=.041)$ and those who stated that there was national discrimination due to COVID-19 exhibited higher anxiety $(\mathrm{F}=6.081, p=.003)$. Participants who were "very worried" about the concerns about other family members getting COVID-19 exhibited the highest anxiety levels $(\mathrm{F}=4.591, p<.001)$. Health behavior scores exhibited a negative correlation with anxiety $(\mathrm{r}=-.117$, $p=.031)$, while depression scores exhibited a positive correlation with anxiety $(\mathrm{r}=.250, p<.001)$.

The factors that exhibited a significant relationship with anxiety in both countries were risk of themselves being infected by COVID-19, risk of dying from COVID-19, national discrimination due to COVID-19, health behaviors, and concerns about other family members getting COVID-19.

\section{3) Factors affecting anxiety in residents of Indonesia and Nepal}

We performed a multiple linear regression analysis to investigate factors affecting anxiety in residents of Indonesia and Nepal. To examine collinearity between the independent variables, the tolerance and variance inflation factor were analyzed; no problems with collinearity were observed $<$ Table3 $>$.

In Indonesia, the factors with a significant effect were trust in hospitals for COVID-19 diagnosis, contracting COVID-19 during the current outbreak, concerns about other family members getting COVID-19, national discrimination due to COVID-19, chronic disease status, experience of purchasing masks, and health behaviors. In Nepal, the factors with a significant effect were trust in hospitals for COVID-19 diagnosis, concerns about other family members getting COVID-19, and depression. Thus, the factors with significant effects in both countries were trust in hospitals for COVID-19 diagnosis and concerns about other family members getting COVID-19 
In Indonesia, the factors with the largest effects on anxiety, in descending order, were concerns about other family members getting COVID-19 $(\beta=.164)$, experience of purchasing masks $(\beta=-.129)$, contracting COVID-19 during the current outbreak $(\beta=.113)$, trust in hospitals for COVID-19 diagnosis $(\beta=.097)$, health behaviors $(\beta=.095)$, national discrimination due to COVID-19 $(\beta=.094)$, and chronic diseases status $(\beta=.083)$. Thus, anxiety was higher in participants who rated the risk of family being infected as higher, who had experience purchasing masks, who rated the contracting COVID-19 during the current outbreak as higher, who had greater trust in hospitals for COVID-19 diagnosis, who performed more health behaviors, who believed that there was national discrimination due to COVID-19, and who had a chronic disease. These variables explained $14.1 \%$ of the variance in anxiety due to COVID-19 among residents of Indonesia.

In Nepal, the factors with the largest effects on anxiety, in descending order, were depression $(\beta=.236)$, health behaviors $(\beta=-.175)$, concerns about other family members getting COVID-19 $(\beta=.159)$, trust in hospitals for COVID-19 diagnosis $(\beta=-.126)$, and national discrimination due to COVID-19 $(\beta=.130)$.

Anxiety scores were higher in participants with higher depression scores, who performed fewer health behaviors, who rated the concerns about other family members getting COVID-19 as higher, and who believed that there was national discrimination due to COVID-19. These variables explained $17.9 \%$ of anxiety due to COVID-19 among residents of Nepal.

\section{Discussion}

Since the first case in December 2019, COVID-19 has spread rapidly throughout the world and caused a massive number of infections and deaths to date. All countries are making every effort to prevent the spread of COVID19, limiting contact between people through measures such as restricting movement, isolation, and closing international borders. The governments of Indonesia and Nepal have also implemented strong COVID-19 prevention policies including closing borders, isolating patients, and restricting the use of public transport, and some policies continue to be implemented. This study aimed to investigate the emotional anxiety among residents of Indonesia and Nepal caused by the sudden changes in the social environment in response to COVID-19 and also analyze the factors affecting anxiety.

Anxiety scores for residents of Indonesia and Nepal were $3.74 \pm 1.1$ points and $3.11 \pm 1.04$ points, respectively, 
meaning that anxiety was higher in Indonesia. Depression scores were also higher among residents of Indonesia compared to residents of Nepal. In a previous study that investigated depression due to national lockdown policies and movement restrictions among Indonesian university students, the prevalence of moderate and severe depression was $27.4 \%$ and $12.9 \%$, respectively [10], which was lower than that in our study, but consistent in indicated that residents were suffering psychiatric and psychological discomfort. In a previous study in Nepal, $14.1 \%$ of residents experienced mild depression and $9.9 \%$ experienced moderate depression due to COVID-19, which was similar to our study (mild depression: $18.3 \%$, moderate depression: 7\%) in showing that residents experienced psychiatric and psychological effects due to movement restriction and COVID-19 [11]. Indonesia developed its first COVID-19 patient later than Nepal, but COVID-19 spread at a much faster rate in the country, and the increase in cases and deaths was much greater. This is thought to be the reason for the high anxiety among residents of Indonesia. It is surmised that residents of Nepal also experienced high anxiety due to movement restrictions and the increase in cases.

When we investigated the factors affecting anxiety among residents of Indonesia and Nepal, in both countries, residents exhibited higher anxiety when they were "very worried" about the concerns about other family members getting COVID-19 and when they reported "high" trust in hospitals for COVID-19 diagnosis. In Indonesia, anxiety was higher among residents who rated the contracting COVID-19 during the current outbreak as "very high," who believed that there was national discrimination due to COVID-19, who had a chronic disease, who had purchased masks, and who practiced health behaviors; in Nepal, anxiety was higher among residents with high depression scores.

In both countries, residents experienced anxiety about family members becoming infected by COVID-19. A study by Lee et al. [12] identified knowledge about COVID-19, health concerns, and fear of COVID-19 infection as factors affecting anxiety [13]. Another study by Wang et al. [14] observed that anxiety and depression increased further among people whose family members have been infected or have a suspected infection, which is consistent with our findings. In our study, most respondents in both Indonesia and Nepal lived in households of 3-5 persons, which suggests that they might think of themselves and their family members as a unit. Thus, they experience higher anxiety when they rated the risk of family members being infected by COVID-19 as higher.

Participants with high trust in hospitals for COVID-19 diagnosis also exhibited high anxiety, which contrasts with the results of a previous study, in which the rapid spread of COVID-19 led to reduced trust in hospitals for COVID- 
19 diagnosis and suspicion about the results of COVID-19 tests [15]. Before the outbreak of COVID-19, trust and satisfaction in hospitals were relatively high among residents of Indonesia [16]. However, since the COVID-19 outbreak, with the declaration of a pandemic by the WHO and the resulting social changes, there has been rapid dissemination of misinformation and fake news about COVID-19. As people have been exposed to this false information unprepared, they began to rebel against government policies or lose trust in COVID-19 test results from hospitals, even leading to dissatisfaction in medical services [17]. Thus, even if the unique circumstances of the COVID-19 pandemic do not harm trust in medical institutions overall, the public may lose trust in services related to COVID-19, leading to increased public anxiety.

In Indonesia, participants who rated contracting COVID-19 during the current outbreak as high and adhered to health behaviors also exhibited high anxiety. This is consistent with a study by Stickley et al. [18], in which anxiety was affected by preventive behaviors such as hand-washing, mask-wearing, coughing into tissues, not touching one's face after touching other objects, canceling holiday plans, and staying at home. People consciously perform preventive behaviors more when they more strongly perceive the risk of disease and consider themselves vulnerable [19]. In our study, we can surmise that individuals developed anxiety that they could be infected as they were continually exposed to information about COVID-19 and that high anxiety led them to perform health behaviors. Participants with experience of purchasing masks and those with chronic disease also exhibited high anxiety. This finding is consistent with a study by Ardan, Rahman, \& Geroda [10], which identified mask-wearing and social activities as factors affecting COVID-19-induced anxiety in Indonesian university students [20]. Countries worldwide are making mask-wearing compulsory to prevent the spread of COVID-19 because blocking contact with saliva or bodily secretions is the most effective method of prevention [21]. However, many countries have not been able to supply enough masks to accompany these policies, and this has heightened public anxiety and led to panic buying [22]. Particularly, developing countries have major difficulties with mask supply, and much effort is needed to purchase masks. This explains why we observed higher anxiety among participants who had an experience of purchasing masks, as we believe that more participants with higher anxiety had an increased desire to purchase masks. Many studies have already confirmed that chronic disease patients exhibit higher fatality from COVID-19, and this has been continually reported by broadcast media [23]; [24]. In one previous study, people with existing diabetes exhibited greater difficulties psychologically accepting COVID-19, which partially agrees with our findings [25]. 
In Nepal, participants with high depression scores exhibited higher anxiety, which is consistent with a study by Chandra, Karki, \& Katwal [26] which investigated depression and anxiety in clinical nurses in Nepal, where nurses with higher levels of depression showed higher anxiety. Depression and anxiety commonly occur together and become more severe as they persist, so they are often measured simultaneously [27]. In Nepal, anxiety increased due to long-term restrictions in relation to COVID-19 and the constant stream of new cases [28], and it can be surmised that this has been accompanied by an increase in the prevalence of depression.

\section{Conclusion}

The COVID-19 pandemic is a source of stress for many people, and the fear of a new disease, concerns about infection, and restrictions to social activities due to isolation are affecting people's emotional anxiety and depression.

In this study of the general characteristics of residents of Indonesia and Nepal, $90.7 \%$ of respondents from Indonesia and $60.4 \%$ of respondents from Nepal were female. The percentage of respondents with a household size of $3-5$ persons was $55.5 \%$ in Indonesia and $68.3 \%$ in Nepal. The mean anxiety score was 3.74 points for residents from Indonesia and 3.11 points for residents from Nepal.

In Indonesia, trust in hospitals for COVID-19 diagnosis, contracting COVID-19, concerns about other family members getting COVID-19, national discrimination due to COVID-19, experience of purchasing masks, chronic disease status, desire for additional information about COVID-19, and health behaviors had statistically significant effects on anxiety. In Nepal, subjective health status, Contracting COVID-19, national discrimination due to COVID-19, health behaviors, risk of family being infected, and depression score had statistically significant effects on anxiety.

The significant factors affecting anxiety in both countries were trust in hospitals for COVID-19 diagnosis and concerns about other family members getting COVID-19. In Indonesia, trust in hospitals for COVID-19 diagnosis, contracting COVID-19 during the current outbreak, concerns about other family members getting COVID-19, national discrimination due to COVID-19, chronic disease status, experience of purchasing masks, and health behaviors were identified as significant factors affecting anxiety. In Nepal, trust in hospitals for COVID-19 diagnosis, concerns about other family members getting COVID-19, and depression score were identified as significant factors affecting anxiety. 
During the COVID-19 outbreak, the United Nations emphasized the importance of mental health, such as constructing mental health policy guidelines [29], and the Inter-Agency Standing Committee published guidelines for mental health that present strategies to provide psychiatric and psychological support [30]. Hence, by implementing policies to deal with new diseases and the spread of disease, governments can not only improve the public's awareness of disease prevention but also remind the public of the importance of prevention and help to stop further disease spread. The governments of Indonesia and Nepal should present policies and guidelines that can prevent psychiatric and psychological problems caused by the spread of COVID-19. These measures will help to prevent and control the secondary damage of the COVID-19 disease.

\author{
Abbreviations \\ WHO: World Health Organization; PSBB: Pembatasan Sosial Berskala Besar; PHQ-9: Patient Health \\ Questionnaire-9; COVID-19: Coronavirus Disease
}

\title{
Ethics approval and consent to participate
}

This study was approved by the Institutional Review Board of Yonsei University (1041849-202005-SB-057-02) and the written informed consent was obtained from all participants.

\section{Consent for publication}

Not applicable.

\section{Availability of data and material}

The data analyzed during this study are not publicly available due to need for confidentiality, but an anonymized version might be available from the corresponding author on reasonable request.

\section{Competing interests}

The authors declare no conflict of interest. 


\section{Funding}

No funding was received to complete this study.

\section{Authors' contributions}

EN designed the original concept of the study. YJ designed the research methodology with supervision from EN and DS. SP implemented the survey and collected the data. YJ and DS interpreted the results. YJ edited the final manuscript. All authors read contributed to the revision of the analysis of the data, the manuscript.

\section{Acknowledgements}

First of all, we would also like to thank all participants from Indonesia and Nepal to develop the research.

Furthermore, we appreciate all the cooperation of collaborators on global COVID-19 trends and international healthcare.

\section{Author details}

${ }^{1}$ Ph.D. course, Department of Health Administration, Graduate School, Yonsei University, Republic of Korea ${ }^{2}$ Post-doctoral, Department of Health Administration, Graduate School, Yonsei University, Republic of Korea ${ }^{3}$ Professor, Department of Health Administration, Yonsei University, Republic of Korea

${ }^{4}$ Vice Dean for Student, Alumni and Collaboration Affairs School of Public Health, Hasanuddin University, Makassar, Indonesia 


\section{References}

1. Davante, R., Lassa, J., Setiamarga, D., Mahfud, C., Sudjatma, A., Indrawan, M., ... \& Gunawan, L. A. (2020). Review and analysis of current responses to COVID-19 in Indonesia: Period of January to March 2020. Progress in Disaster Science, 100091.

2. President of the Republic of Indonesia. (March.31.2020). Government Establishes Public Health Emergency Status. Retrieved from https://www.presidenri.go.id/siaranpers/pemerintah-tetapkan-status-kedaruratan-kesehatan-masyarakat/

3. Tika R Pradhan. (March 23, 2020). Nepal goes under lockdown for a week starting 6am Tuesday. The Kathmandu Post. Retrieved from https://kathmandupost.com/national/2020/03/23/nepalgoes-under-lockdown-for-a-week-starting-6am-tuesday

4. Spielberger, C. D. (1972). Anxiety: Current trends in theory and research: I.

5. American Psychological Association (APA). (2020). Anxiety, sadness may increase on anniversary of a traumatic event. Retrieved from https://www.apa.org/topics/anniversary-traumatic-event

6. Cao, W., Fang, Z., Hou, G., Han, M., Xu, X., Dong, J., \& Zheng, J. (2020). The psychological impact of the COVID-19 epidemic on college students in China. Psychiatry Research, 112934.

7. Li, J., Yang, Z., Qiu, H., Wang, Y., Jian, L., Ji, J., \& Li, K. (2020). Anxiety and depression among general population in China at the peak of the COVID-19 epidemic. World Psychiatry, 19(2), 249.

8. Wang, C., Pan, R., Wan, X., Tan, Y., Xu, L., Ho, C. S., \& Ho, R. C. (2020). Immediate psychological responses and associated factors during the initial stage of the 2019 coronavirus disease (COVID-19) epidemic among the general population in China. International journal of environmental research and public health, 17(5), 1729.

9. World Health Organization. (2020). WHO Coronavirus Disease (COVID-19) Dashboard. Retrieved from https://covid19.who.int/

10. Ardan, M., Rahman, F. F., \& Geroda, G. B. (2020). The influence of physical distance to student anxiety 
on COVID-19, Indonesia. Journal of Critical Reviews, 7(17), 1126-1132.

11. Gupta, A. K., Sahoo, S., Mehra, A., \& Grover, S. (2020). Psychological impact of 'Lockdown' due to COVID-19 pandemic in Nepal: An Online Survey. Asian Journal of Psychiatry.

12. Lee, S. A., Jobe, M. C., Mathis, A. A., \& Gibbons, J. A. (2020). Incremental validity of coronaphobia: Coronavirus anxiety explains depression, generalized anxiety, and death anxiety. Journal of Anxiety Disorders, 74, 102268.

13. Li, J., Yang, Z., Qiu, H., Wang, Y., Jian, L., Ji, J., \& Li, K. (2020). Anxiety and depression among general population in China at the peak of the COVID-19 epidemic. World Psychiatry, 19(2), 249.

14. Wang, Z. H., Yang, H. L., Yang, Y. Q., Liu, D., Li, Z. H., Zhang, X. R., ... \& Wang, X. M. (2020). Prevalence of anxiety and depression symptom, and the demands for psychological knowledge and interventions in college students during COVID-19 epidemic: A large cross-sectional study. Journal of Affective Disorders, 275, 188-193.

15. Choi, Si Ung. (March.21.2020) Died the high school student aged 17 had tested 13 times of COVID-19 test... Why. [숨진 대구 17세 고교생 코로나 19 검사 열세번...왜그렇게 많이 했녀.

영남일보. https://www.yeongnam.com/web/view.php?key=20200320010003803

16. Dioso, R., \& Yuliawati, Y. (2018). Clients' satisfaction on quality of services in a hospital setting in Indonesia. Open Journal of Nursing. 1. 40-48.

17. KTV Korea Broadcasting. (March.16.2020). The credibility of COVID-19 test in Korea is decreased? The truth? [ 국내 코로나검사 신뢰성 떨어졔?…사실은?].

\section{http://www.ktv.go.kr/news/latest/view?content id=595438\&unit=277}

18. Stickley, A., Matsubayashi, T., Sueki, H., \& Ueda, M. (2020). COVID-19 preventive behaviors among people with anxiety and depression: Findings from Japan. Public Health.

19. Hayden, J. (2017). Introduction to health behavior theory. Jones \& Bartlett Learning.

20. Cheng, V. C., Wong, S. C., Chuang, V. W., So, S. Y., Chen, J. H., Sridhar, S., ... \& Yuen, K. Y. (2020). 
The role of community-wide wearing of face mask for control of coronavirus disease 2019 (COVID-19) epidemic due to SARS-CoV-2. Journal of Infection.

21. Chandra, A., Karki, P., \& Katwal, G. W. B. J. (2019). Prevalence and Measurement of Anxiety and Depression in Working Nurses in Nepal: A Reflection of Professional Hazard in Low Income Nation.

22. Zhang, Y., \& Zhou, R. (2020). Promote social distancing and prevent panic buying during the epidemic of COVID-19: The contributions of people's psychological and behavioural factors.

23. Centers for Disease Control and Prevention. (2020). People with Certain Medical Conditions. Retrieved from

https://korean.cdc.gov/coronavirus/2019-ncov/need-extra-precautions/people-with-medical$\underline{\text { conditions.html }}$

24. Pal, R., \& Bhadada, S. K. (2020). COVID-19 and non-communicable diseases. Postgraduate Medical Journal.

25. Singhai, K., Swami, M. K., Nebhinani, N., Rastogi, A., \& Jude, E. (2020). Psychological adaptive difficulties and their management during COVID-19 pandemic in people with diabetes mellitus. Diabetes \& Metabolic Syndrome: Clinical Research \& Reviews, 14(6), 1603-1605.

26. Karki, P., Katwal, G. W., Chandra, A., \& Chandra, A. (2020). Prevalence and Measurement of Anxiety and Depression in Working Nurses in Nepal: A Reflection of Professional Hazard in Low Income Nation.

27. Risal, A., Manandhar, K., Linde, M., Steiner, T. J., \& Holen, A. (2016). Anxiety and depression in Nepal: prevalence, comorbidity and associations. BMC Psychiatry, 16(1), 102.

28. Gupta, A. K., Sahoo, S., Mehra, A., \& Grover, S. (2020). Psychological impact of 'Lockdown' due to COVID-19 pandemic in Nepal: An Online Survey. Asian Journal of Psychiatry.

29. United Nations. (2020). Policy Brief: COVID-19 and the Need for Action on Mental Health. Retrieved from https://www.un.org/sites/un2.un.org/files/un_policy_brief-covid_and_mental health_final.pdf

30. Inter-Agency Standing Committee. (2020). IASC Guidance on Operational considerations for Multisectoral Mental Health and Psychosocial Support Programmes during the COVID-19 Pandemic. 
Retrieved from https://interagencystandingcommittee.org/iasc-reference-group-mental-health-andpsychosocial-support-emergency-settings/iasc-guidance 
Figures
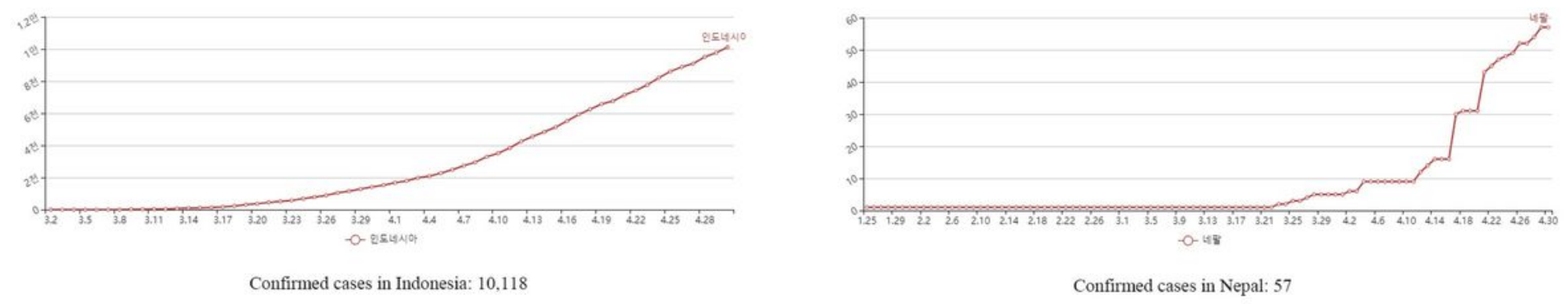

Figure 1

Confirmed case in Indonesia and Nepal (30. April. 2020)

\section{Supplementary Files}

This is a list of supplementary files associated with this preprint. Click to download.

- Additionalfile1.docx 